\title{
Body integrity identity disorder (BIID): How satisfied are successful wannabes
}

\author{
Sarah Noll ${ }^{1,2,}$, Erich Kasten ${ }^{1,2}$ \\ ${ }^{1}$ Institute of Psychology, Hildesheim, Germany; Dept. Of Neuropsychology, Hamburg, Germany \\ ${ }^{2}$ University of Hildesheim, Hildesheim, Germany; Medical School Hamburg, Hamburg, Germany
}

\section{Email address:}

SarahNoll@gmx.de (S. Noll), EriKasten@aol.com (E. Kasten)

\section{To cite this article:}

Sarah Noll, Erich Kasten. Body Integrity Identity Disorder (BIID): How Satisfied are Successful Wannabes. Psychology and Behavioral Sciences. Vol. 3, No. 6, 2014, pp. 222-232. doi: 10.11648/j.pbs.20140306.17

\begin{abstract}
Background: People suffering from Body Integrity Identity Disorder feel the intensive wish for an amputation of one limb or another kind of handicap. Due to ethic and juristic reasons, the desired surgery is difficult to realize. In spite of these problems several patients were able to achieve the wished amputation, in most cases with a cash-paid surgery in a less developed country. Our study examined whether these patients are sufficient with the amputation in the long run. Methods: We found 21 operated BIID-people (18 men, 3 woman; 27 - 73 years old, average 53.5 years) and interviewed them with a questionnaire. Here, we asked e.g. about quality of life and mental states before and after their surgery, the integration into the social environment, changes of their own dreams, the desire for further surgery and the presence of phantom sensations. Results: Psychological therapy, psychopharmacological medication, and relaxation techniques have had little effect and sometimes increased the desire. None of the patients regretted the surgery and a change for the better was seen in almost all areas of life. There were several problems regarding the quality of life, but they were estimated as bearable in contrast to the happiness to have fulfilled the wish. Many told their closer family members the true reasons of their amputation. Phantom limb feelings were reported, what contradicts the theory of BIID as a limb not embedded in the brain's body-schema. After the operation most of the participants dreamed of themselves with an amputated body. The majority of the interviewee did not want further restrictions. Conclusions: These results point to the fact that the often assumed negative consequences of an amputation or further surgery do not occur. Thus, a realization of the wish of a person affected by BIID could be a possible form of therapy for patients, when other therapies have shown no effects.
\end{abstract}

Keywords: Body Integrity Identity Disorder, BIID, Body Incongruence Disorder, Apotemnophilia, Amputation, Xenomelia, Phantom Limb Pain

\section{Introduction}

A person suffering from Body Integrity Identity Disorder (BIID) has an entire body, but the perception of the own identity is that of an amputated or otherwise impaired person and they feel a strong urge for an amputation or another kind of operation [see e.g. 1, 2, 3, 4, 5, 6, 7, 8, 9, 10]. They named themselves as "wannabes" (for: want to be). These persons are absolutely aware about the absurdity of their wish; they do not show any psychotic symptoms and usually there are no signs of delusion, obesity or personality disorders [3, 9]. Furthermore, these persons do not want to be seen as handicapped after the surgery, they strive for a rather self-determined life. Likewise BIID should be distinguished from Body Dysmorphic Disorder, because in BIID the subject don't see the concerned limb as ugly, they just have the feeling it is not truly belonging to their body. While in BDD all parts of the body come into question, the goal of the BIID wish are mostly legs and arms. There are some parallels to the Gender Identity Disorder, in which people have strong feelings that their outer sexual organs don't fit to their mental identity. From this point of view, Prof. Dr. Michael First [3] concludes that this phenomenon has to be called "Body Integrity Identity Disorder" and should not subsumed under the older term "apotemnophilia" as a paraphilia, which had turned the focus on a sexual component [11]. Without any question, several of these persons have erotic feelings in respect to amputations, but this sexual component is not found in all individuals with BIID [12, 13, 14]. Currently McGeoch and co-authors [15] named this syndrome "Xenomelia". Body Integrity Identity Disorder (BIID) is a 
rare mental disorder, under 680 randomly chosen people we found only 1 with this syndrome, but we saw several kinds of pre-stages: $7.9 \%$ of the general population know the wish to get rid of a part of the body, because it does not seem to belong to the self and $2.1 \%$ have had these feelings more than once [16].

Even competent professionals are often unable to identify BIID clearly [17]. The disorder manifests itself in the desire to obtain a physical impairment, and then to feel better with a new gained identity as an amputee. In addition to amputations, the desired impairments are often palsy of arms or legs. Currently discussed is, whether the desire for incontinence, chronic illness as e.g. diabetes mellitus, or the loss of one sense as e.g. deafness or blindness should be summarized under BIID [4, 9, 18$]$.

To get closer to the feelings of a handicapped person, people suffering from BIID simulate their desired impairment using crutches or a wheel-chair [e.g.: 3, 9, 10]; this behavior is called "pretending". Usually physicians refuse the operation; then the urge can be so strong that the patients try to achieve their desired physical state on their own, e.g. with a self-made guillotine, chainsaws, freezing the limb in dry ice or something comparable [see e.g.: 3]; occasionally a patient does not survive such a self-made trial. But most amputations are made by physicians in hospitals in developing countries, paid by cash and claimed to be the result of an accident or infection.

Previously, the effects of therapies (e.g. antidepressants, behavioral therapy, psychoanalysis) were examined in some single case studies $[19,20,21]$. Most of the authors came to the conclusion that these treatments helped the patients to cope with their strange urge, but in nearly all cases the desire doesn't vanish entirely. The BIID sufferers often like it to compare their symptoms with Gender Identity Disorder (GID), for which our society allows an operation to change the secondary gender organs. In contrast to this opinion, several scientists argue that GID surgery doesn't produce a handicap and it is unclear, whether BIID people are satisfied with their amputation in the long run. In addition, critics often express the assumption that there is a "looping effect" after the operation, so that more surgeries are desired [22], comparable to Body Dismorphic Disorder or mania operativa.

Currently there is a livid discussion, whether amputations in BIID should be done legally under strict conditions [23, 24, $25,26,27,22,28,29]$. The decision to solve this question can only be made by examinations of "successful wannabes", i.e. persons who achieved the desired handicap. Therefore, for the first time, in the here presented study we have analyzed the consequences of an actual realization of the desired impairment in a larger group. Main task of our work was to solve the question how the symptoms short after an operation changed, last these feelings for years or do the subjects then want further operations? Another question was to find out what kind of therapies these peoples tried before the amputation.

A further important aspect asked for the social embeddings of these persons, and to which extent they talk about their problem with family members, relatives, friends or colleagues.

A current explanation for the cause of BIID is a dysfunction of the parietal lobe, in which the body is represented [30, 31, 32]. Ramachandran [33] demanded that BIID-sufferers are the opposite of people with amputations due to real accidents. The latter often have phantom limb feelings in the amputated arm or leg, while in BIID the limb exists, but seems not to be animated in higher brain structures, where the borders of the body are represented [2]. In MRI-studies McGeoch and co-authors [15] found a missing representation of the concerned limb in the upper part of the parietal lobe. If this theory is right, amputated BIID patients should not have any phantom limb feelings.

In addition, if the limb is not represented in the brain, it could be that the affected limb does not longer occur in the dreams after the surgery [34]. Therefore, we collected data of the perception of the own body while dreaming.

\section{Methods}

The study design was approved by the ethics committee of the University of Luebeck (Ref.: 10/051) and was in accordance with the regulations stated in the Declaration of Helsinki. For our investigation we used a questionnaire either as paper-pencil- or online version. At first the participants were informed about the pseudonymity. Subjects were persons with BIID who already had achieved the desired operation. To be really sure that only persons with amputations answered our questionnaire, the participants had to answer specific questions about their situation. Several of the participants were known face-to-face with one of the authors. The participants were exclusively contacted in BIID internet forums via e-mail and received either the English or German versions of the questionnaire. Thus, there was little chance a not amputated BIID-subject was filling out the questionnaire.

\subsection{Sample}

Twenty-one participants send back the survey. This sample included 18 men $(85.7 \%)$ and three women (14.3\%). The average age was 53.5 years $(27-73$ y., SD: \pm 12.8 y.). $76.2 \%$ were heterosexual, $9.5 \%$ homosexual and $14.3 \%$ bisexual. All, except one, had an education degree higher or equal to the specialist college. The majority is working in occupations which are attended by high responsibility. More than a half of them $(52.4 \%)$ were married, $14.3 \%$ lived with their partner or they were single, $9.5 \%$ lived in a relationship, but not in the same household with their partner and $9.5 \%$ were divorced. Fifteen persons $(71.4 \%)$ had children, the number varied from one to four. The achieved impairments are shown in Table 1.

\subsection{Instruments}

In the questionnaire some items had the level of nominal scale (e.g. experiences of phantom limb feelings), most of the questions used scales either $0 \rightarrow 100$ or $-50 \rightarrow+50$. Additional 
answers in free text were related to the reasons of their desire, the feelings the subjects have had about the surgery, the advantages and disadvantages of daily living after the surgery and an example of a dream they had. Analysis was made with SPSS. Because the sample was small, in most groups homogeneity of variances was missed and there was no normal distribution of the data, we reckoned non-parametrical tests.

Test-objectivity was given because we used a standardized printed form of a test. We investigated the reliability of our test with the correlation of some similar question, which appeared on different pages of the questionnaire: "Do you had mental disturbances due to BIID before the amputation" (scale 0 100) and "How would you judge yourself personally before amputation?" (scale -50 to +50 ). For depressive disturbance vs. depression/happiness before the operation the correlation was $r=-0.51 \quad(p<0.05)$ and for anxiety disorder vs. anxiety/courage before the operation was $\mathrm{r}=-0.45(\mathrm{p}<0.05)$. Inner contingency for the parts of questions about (1) feelings before the operation were Cronbach's Alpha $=0.94$; (2) private, occupational, health and sexual situation before surgery 0.76 ; (3) for feelings after the operation 0.82 ; (4) for private, occupational, health and sexual situation after the operation 0.47 ; (5) for satisfaction with the new body 0.80 ; and (6) for phantom limb pain/feelings was Cronbach's Alpha $=0.68$. Therefore in our mind the questionnaire had a sufficient reliability.

Table 1 Description of the sample.

\begin{tabular}{|c|c|c|c|c|c|}
\hline No & Age & Gender & Handicap & Year of operation & $\begin{array}{l}\text { Operation } \\
\text { from... }\end{array}$ \\
\hline 1 & 57 & male & $\begin{array}{l}\text { (incomplete) palsy } \mathrm{T} 5 / 6 \text {, leg orthotics (long lasting wearing leg splints } \\
\text { without possibility to move) }\end{array}$ & 2010 & - \\
\hline 2 & 48 & male & High incomplete paraplegia & 2009 & -- \\
\hline 3 & 59 & male & Left above the knee amputation (LAK) & 2001 & self-induced \\
\hline 4 & 68 & male & Left above the knee amputation (LAK) & 2008 & physician \\
\hline 5 & 37 & male & Acampsia of the right knee by operation & 2009 & physician \\
\hline 6 & 65 & male & Right above the knee amputation (RAK) & 1998 & physician \\
\hline 7 & 47 & male & Left above the knee amputation (LAK) & 2010 & physician \\
\hline 8 & 67 & male & Left below the knee amputation (LBK) & 2009 & physician \\
\hline 9 & 73 & male & Right above the knee amputation (RAK) & 2009 & physician \\
\hline 10 & 63 & male & Left above the knee $(\mathrm{LAK})+$ amputation of the left half forefinger & 2000,2004 & physician \\
\hline 11 & 46 & female & Right above the knee amputation (RAK) & 2003 & self-induced \\
\hline 12 & 52 & male & Left above the knee (LAK), Right above the knee amputation (RAK) & 1997 & self-induced \\
\hline 13 & 59 & male & Left above the knee amputation (LAK) & 1999 & self-induced \\
\hline 14 & 38 & male & Right above the knee amputation (RAK) & 2001 & self-induced \\
\hline 15 & 68 & male & Left above the knee amputation (LAK) & 2009 & physician \\
\hline 16 & m.d. & male & Left above the knee amputation (LAK) & 2005 & -- \\
\hline 17 & 41 & male & Double above the knee (DAK) + right below the elbow amputation (RBE) & m.d. & friend \\
\hline 18 & 27 & male & Double above the knee amputation (DAK) & 2008 & friend \\
\hline 19 & 67 & male & Loss of teeth \& amputation of both feet & 2007 & physician \\
\hline 20 & 43 & female & Left below the elbow amputation (LBE) & 2012 & physician \\
\hline 21 & 46 & female & Double above the knee (DAK) & 2010 & self-induced \\
\hline
\end{tabular}

\section{Results}

\subsection{Motivations}

As in other studies our subjects were unable really to explain their motives for their desire for amputation. Typical, but often cloudy answers were (not all answers are portrayed): "To raise my inner body feelings, to step out of the bondages of a schematic life with always the same cycles. I perceived my legs as of no relevance."; "The otherness always fascinated me."; "It supports my identity, I recognized myself even before the operation as a handicapped man. It's the picture I've of myself."; "Sometimes I felt envious, when I saw amputees; found it fascinating to be this way. There are no concrete reasons, I searched for them, but with time going on I found out that I'm liking myself only as an amputee. Leg/arm were disturbing."; "I have some ideas, but I do not know if they re correct. Perhaps I believed that I was not OK, and came to believe that if I were different I would be OK. Perhaps I observed that people with disabilities received sympathy and I did not. Perhaps it was because my mother was overprotective, and did not want me to run and play."; "I have no idea how, why or where my wish/need to be an amputee came from and I don't know the cause either. I believe the desire/wish/need comes from some genetic mix up in my brain. It's not something I wanted to have to deal with for most of my life."; "Since very young age I knew that my right leg is not belonging to me and I want to get rid of it at all costs."; "Since my early childhood I have had an appetence and yearning to live as an leg-and arm-amputee. Lifelong this desire was very strong. Always I imagined to have an amputation beginning from my left thigh and I've had this body scheme before my inner view. The yearning for this ideal body image grew with increased age; at last so much, that-in regard to my age-I decided to look for a solution, because I think help from medicine will not be possible for a long time, i.e. for the time I have in front of me, having an age in the third decade of my life. I only wanted to shake off the pressure and the suffering from BIID and to have a liberate, released and sufficient life in the future. Out of my view, instead of other 
causes for an amputation (e.g. diabetes, tumor and so on), I was suffering from BIID, which I haven't had in my grip and which hampered me to live a good life. To get healthy, the amputation was necessary. Already as a child I had seen several amputees, especially in the open air bath, and instantly admired, how they handle their handicap. I was absolutely fascinated and wished to be like these people. I felt drawn to them and felt always well, when I watched them."; "...When I was a young child, I pretended that my stuffed animals had missing legs, or I immobilized their legs. Anyway, it got to a certain point where I had to proverbially get off the pot, and it basically came down to a question of being happy. I figured one way or another, how I could be happy, but on a long term I could only be happier without legs.” (...)

\subsection{Erotic Component}

Several, but not all subjects wrote they feel an erotic component as e.g.: "In puberty there came an additional sexual component of about 50\% weight."; "In addition the stump is erotic."; "When my first wife suffered from an osteo-sarcoma and lost her left leg, my life was perfect. The stump became part of our sexual satisfaction."; "There is an aesthetic sexual complex, in addition I find the kind of walking very erotic."; "The otherness, the stump stimulated me. Pretending always resulted in masturbation"

\subsection{Estimation of the Affected Part of the Body}

It was discussed, whether BIID has similarities with Body Dysmorphic Disorder (BDD); in the latter people find a part of their body ugly and try to get plastic-surgery. We therefore asked: "How much differed the body part you had amputated from the rest of your body?" The mean of all answers on a -50 to +50 scale showed a tendency to the negative half in all dimensions:

Very unaesthetic / very aesthetic: $-06.7 \pm 25.0$

Very soulless / very soulful: $-13.5 \pm 28.9$

Not belonging / very belonging to me: $-24.8 \pm 35.2$

Very disgusting / very beautiful: $-08.6 \pm 28.5$

\subsection{Ways to Get Rid of the Affected Limb}

One of the most interesting questions was, how the subjects achieved their handicap and what have they told their social environment?

Nineteen subjects told us about their goal achievement. Ten of them had a surgery, in most cases in a foreign country. They told their environment about a medical problem with the concerning limb. Eight subjects have achieved their amputation caused by a deliberate accident. They used dry ice, a pellet-gun, self-induced infections, medicines or a railway-coach to roll about the leg. The excuse they invented was mostly an accident-story. One person had a real accident and therefore no need to invent an excuse.

\subsection{Changes of Quality of Live after the Achieved Handicap}

Another important task of this study concerns the question, if there is any change of the general quality of life after the surgery? For this purpose, we asked questions about the situation before and after the operation using scales from -50 to +50 . All participants judged their situation as better after the surgery and we found significant improvements in every field (see Tab. 2).

Before the amputation, most of the participants $(66.7 \%)$ suffered very much from not having the desired operation (mean on a 0 to 100 scale: $93.5 \pm 11.8$ ). After the operation none of the persons with BIID regretted the amputation or surgery: For this question, without any variability, everybody had chosen zero (i.e. absolutely not). Furthermore, the affected persons were very happy with their bodies after the change (mean $88.1 \pm 19.7$ ), reached their ideal body image (mean $87.6 \pm 18.95$ ) and felt complete with their body (mean $94.0 \pm 13.1)$.

In addition, we had asked how they assessed themselves personally before and after the amputation. We found significant improvements after surgery for the dimensions depression / happiness, introversion / extraversion, anxiety / courage, nervous / calm, aggressive / peaceful, lethargic / enthusiastic and wretched / self-confident (see Tab.3).

Furthermore persons with BIID do not feel handicapped after the surgery: On a 0 to 100 -scale the mean was $9.1 \pm 11.4$. In addition they feel less pain. The mean of the answers on the question, to what extent they are restricted in the quality of life due to an amputation-pain was $12.1 \pm 21.5$ on a $0-100$ scale.

Table 2 Changes of satisfaction in activities of daily living before and after the achieved handicap on a -50 to +50 scale.

\begin{tabular}{llll}
\hline & $\begin{array}{l}\text { Before (mean } \\
\mathbf{\pm} \text { SD) }\end{array}$ & $\begin{array}{l}\text { After (mean } \\
\pm \text { SD) }\end{array}$ & Wilcoxon Test \\
\hline general life situation & $-20.5 \pm 24.4$ & $45.2 \pm 7.5$ & $\mathrm{p}<.01$ \\
job satisfaction & $20.5 \pm 32.0$ & $39.5 \pm 21.8$ & $\mathrm{p}<.01$ \\
private life & $3.8 \pm 27.8$ & $43.8 \pm 8.7$ & $\mathrm{p}<.01$ \\
health status & $20.0 \pm 32.7$ & $42.4 \pm 12.2$ & $\mathrm{p}<.05$ \\
sexual satisfaction & $15.2 \pm 25.2$ & $35.2 \pm 22.5$ & $\mathrm{p}<.01$ \\
body identification & $-21.4 \pm 29.0$ & $47.6 \pm 5.4$ & $\mathrm{p}<.01$ \\
\hline
\end{tabular}

Table 3 Changes of emotions before and after the achieved handicap on a -50 to +50 scale.

\begin{tabular}{llll}
\hline & $\begin{array}{l}\text { Before (mean } \\
\mathbf{\pm} \text { SD) }\end{array}$ & $\begin{array}{l}\text { After (mean } \\
\mathbf{\pm} \text { SD) }\end{array}$ & $\begin{array}{l}\text { Wilcoxon } \\
\text { Test }\end{array}$ \\
\hline depression/happiness & $-16.5 \pm 23.2$ & $41.0 \pm 15.8$ & $\mathrm{p}<.01$ \\
introversion/extraversion & $-7.0 \pm 22.3$ & $24.3 \pm 14.7$ & $\mathrm{p}<.01$ \\
anxiety/courage & $-6.8 \pm 16.4$ & $27.0 \pm 17.5$ & $\mathrm{p}<.01$ \\
nervous/calm & $-16.0 \pm 20.4$ & $36.2 \pm 16.3$ & $\mathrm{p}<.01$ \\
aggressive/peaceful & $-1.0 \pm 26.5$ & $37.6 \pm 17.5$ & $\mathrm{p}<.01$ \\
lethargic/enthusiastic & $-6.5 \pm 26.6$ & $36.0 \pm 18.5$ & $\mathrm{p}<.01$ \\
wretched/self-confident & $-5.0 \pm 24.1$ & $40.5 \pm 15.3$ & $\mathrm{p}<.01$ \\
\hline
\end{tabular}

\subsection{Disadvantages Due to the Achieved Handicap}

Asked about the disadvantages of a live with a handicap, they answered in free text (not all answers are reproduced here): "Now I need more power and more time. My body changes (I put on weight!), living is more expensive (orthotic-device, wheel-chair, fitting my house and my car to the handicap etc.)."; "I need the double of time for my personal toilet. I'm sweating more on hot days, especially in 
the prostheses. Sometimes people found me ugly when I'm without prostheses."; "Rather few. I can't walk as far (yet) without getting tired and have to use a 'scooter' for longer walks. I have had some problems on and off with my prosthesis. I find it harder to walk on a floor that is cluttered (as floors are often by my young grandchildren) or on uneven terrain. But actually my amputation has resulted in only rather minor difficulties and adjustments. And I have enjoyed working to find ways to overcome these minor difficulties."; "Absolutely nothing. Things I can't do now without problems are secondary and I'm missing nothing."; “Absolutely no disadvantages. With my 'wheeli' I can reach every point and can do what I want."; "Need more surgery because the doctors botched the first one. Was treated very badly in the hospital in general, and still dealing with some stress stuff from that too. “ (...)

\subsection{Advantages Due to the Achieved Handicap}

Asked about the advantages of a live with a handicap, our subjects answered: "Since living permanently in a wheel-chair (July2010) I'm free of depressions und can enjoy my life. Even in the wheel-chair I'm able to work in my occupation. Before this, BIID pressed me into a double-life. Now this compulsion is gone. The more atrophy I'm getting in my legs, the easier it becomes for me."; "Feeling of identity-now I'm much more myself, more openness und feelings of lightness in my life; I can meet people more openly now. I see my job in a new way and find more power and creativity in daily living."; "At last I found myself relaxed, happy, satisfied. The knowledge I have done the right thing."; "My preoccupation with BIID has been markedly resolved. While I am still interested in amputation related issues, they don't dominate my thoughts or distract me from other interests, obligation and the like. As a consequence I am much more content, much less irritable, much more productive professionally, and a much better member of my family. In addition, I really enjoy being an amputee. I enjoy the challenges of finding new ways to do things, to become stronger and more fit. I like crutch walking and using my prosthesis, I like my stump. Basically I am just much happier with myself."; "When I'm looking in the mirror today, I can see me in the way I always wanted to be. I like the stump in my thigh. I don't need to think about amputations any further. I can stop to hide my feelings before my family. I'm calmer and more relaxed. I got more life-energy."; "Finally without the need to think the whole day about how I will become one day an amputee." (...)

\subsection{Emotions and Thoughts Short before the Operation}

The next questions we asked were whether there was a change of feelings before, directly after, one year after amputation and now. Nearly all participants wrote they were afraid before the surgery. This fear disappeared fast after the surgery and was generally replaced by euphoria. After weeks for most of the participants this euphoria changed to normal feelings, while others demanded it goes on until now. The answers for this question were homogenous insofar as all participants said, they are happier today, feel calmer and more content.

Short time before the operation the subjects uttered following thoughts and feelings: "In the years before the operation I've had a double life. I always felt anxious that somebody trapped me, when I was pretending. Because I have a job in the public, I was anxious then to be punished for my life. Short time before the operation I've had a very positive talk with my boss, this helped a lot. The days before the operation were full of joy and hope. I've had no fears, slept well and was able to think in a constructive manner."; "Neutral at first, because I knew that there would be no palsy due to the operation of the spinal disc. I always was realistic. I felt disappointed because the operation went fine without any complications and nothing had happened in the direction of my desire. Then, two weeks later I had an accident with the result of a paraplegia. Directly thereafter I had feelings of happiness."; "Many question marks, how life will go on after the amputation, and how my people will get along with it. Insecurity for details, but no anxiety."; "Unable to understand my fortune. For years I've worked for this day and suddenly, now it was here! Everything felt normal and sure. The stuff in the hospital treated me totally normal; I was enjoyed how fast and normal everything ran. I've had fears to be seen as a lunatic, but this was absolutely not the case."; "Excitement. Will I be relieved? Will I just want more amputations? Will I have complications or just even die? Could I or the surgeon be found out and get in trouble? Am I making a mistake? Is it crazy to do this? I have wanted this for so long, I would hate myself for the rest of my life if I back out now."; "When the physician explained me that they must amputate the right leg, I was nearly unable to hide my joy. I've reached my goal. Because the amputation was done as an emergency, they made the paperwork short after the talk, and the anesthetist discussed the narcosis with me. That day I've not eaten so much and therefore they could prepare me for the operation immediately. Within 2 hours I had lost my leg. I've had a lot of respect before the organization, but my happiness was very huge."; "Joyful equanimity, during the spinal anesthesia I was awake and watched.”; "In one word: EXITED.” (...)

\subsection{Emotions and Thoughts Short after the Operation}

Feelings and thoughts directly after the operation were: "I wasn't able to understand my luck, like the motto: 'How have I deserved this'-or is there still any higher power that filled my life with luck and life? I was not able to understand why the 'fate' chose me under so many people suffering from BIID. Because of this I recognized happiness and thankfulness."; "When I awoke in the room, I felt relaxation and relief, lightness as never before. I had the feeling: 'At last this is forever!' I can't stop to look at the leg. I felt light as a feather. I felt totally normal, as if it ever should have been this way."; "When I woke up, the first I recognized was that BIID was gone. For sure this was the most overwhelming feeling in my life. I suffered for more than 40 years from BIID-and now it's vanished."; "I was elated. I woke up just after the amputation 
when I was returned to my room in the hospital. My wife and the surgical team were all together eating and talking when they brought me into the room. I awakened briefly and they said the surgery was done and I said thank you and fell back to sleep. The next morning they woke me up and I looked down where my leg should have been and saw that it was gone. I was extremely happy. I could still feel my leg, so I had to actually look to make sure it was gone. I was ecstatic! I felt like a teenager again, even though I was 56 years old! I was as happy as I'd ever been and I was really horny, too! I felt extremely great for the next 6-8 weeks, then things started to return to the new "normal". I am still happy after over 7 years as an LAK amputee. The only regret I have is that I only wish I could have had my amputation done when I was in my early teenage years or my early twenties. I lost so much of my life because I had to endure all those long years without my needed amputation and stump!"; "After a well-slept night I was en route with my crutches, in a rent bungalow at the sea."; "Have I really achieved it? Am I an amputee? This was my first thought. Immediately I looked and saw with great relief and happiness that I had reached my goal. Simply fantastic, now I have the body I always wanted to own. I was happy, full of joy, felt good and sufficient, that everything was as it was. In addition I suffered no pain.”; "In one word: FINALLY.” (...)

\subsection{Emotions and Thoughts One Year after the Operation}

Feelings and opinions about the operation one year later were: "Since about 11 months I'm living permanently with orthotics or wheel-chair. I live my everyday life freed from burnout and depression, meet friends without anxiety, can enjoy trivial things. I've got a new view of life, enriching me. In some way the feeling: I arrived."; "This is the only single truth, you feel well, try to savor as long as possible, perhaps it will work with the second leg as well."; "I'm still feeling this lightness. I recognize a total normality. Sometimes I'm looking at myself in the mirror und feel to be attractive. I can go to people better and with more confidence. At any time I would repeat this operation, only sometimes I regret I've not had it 10 years earlier."; "I am happier than I was ever before. I am surprised how easy it is to be an amputee. I am surprised how little other people care that I am an amputee, or that I had chosen to be one. I no longer need to do something all the time to escape from my bad feelings about myself. I am confident that if anyone tries to abuse me again, I will have the strength and courage to prevail. I no longer feel guilty or ashamed to be what I am. People treat me much better because I do not appear guilty or unhappy."; "More than happy. Since the first day I felt 'complete'. The adaption of the prosthesis was without any problems and today I can walk without crutches."; "I wish they'd done a good job with the operation. They focused too much effort on preserving bone length, and left me with very little soft tissue at the ends of my stumps, they left the bone ends messy, and they just chopped the nerves and let that be that, so I was in a lot of pain and having to deal with keep money coming in, so I wouldn't be completely uninsured and destitute. Oh, and they sutured things up so that my right femur's at the wrong angle and my muscles go clicking painfully over the bone ends every time I move. It's especially frustrating because I was doing really well on prostheses before the pain problems kicked in, and I have a nice pair of $C$-Legs just sitting in the closet that I can't use at all, other than to just stand in." (...)

\subsection{Emotions and Thoughts Now}

Asked for the feelings today, our subjects wrote: "All as said above. Only to say in the meantime I learned that my luck will stay und this makes me more than happy. 'Hurray', now I'm the human I always wanted to be and can continue and nobody can take away my wheel-chair! The advantages outweigh the disadvantages by far."; "Would always do the same. Never regretted and I am proud with my stump. Get very excited, when somebody speaks about it. Touches of the stump are like positive electric impulses.”; "Rarely questions/concerns mix between my positive experiences. But the latter prevail I never wanted not to be amputated. I rather should have had the amputation with 25 or 30 or even earlier; through this much quality of life was lost. To see my reversed image in the mirror was never a topic, today it is. It's a shame that after a careful examination, a legal amputation for people like me is hampered and people with psychological strain have to lay on railways and risk their life. The real operation was more a recovery, only one day some pain."; "Life keeps getting better. I feel a bit envious when I see someone with an AK amputation but I am perfectly fine as I am and I do not need anything else. My wife and I love each other more than ever before."; "After more than 7 years as an LAK amputee, I'm still extremely happy and content with my amputation and my stump! I can't imagine NOT being an amputee. Ifeel as though my body is now in tune with my mind! I do not regret my choice to get an amputation at all. Yes, there are times where it is and can be a challenge, it's still better than all the suffering I lived through until I got my amputation. I love waking up and seeing my stump there. My stump is still very erotic and I do not suffer from any pain at all, including no phantom pains. I have phantom sensations, but not as many as I once had. I miss them a lot as they really reminded me that I was an amputee and they felt really good. The sensations I have now, help me to bring my Phantom-Leg back to me. So, I can still 'feel' my missing leg whenever I choose!"; "I still need to get surgery to fix things, but I'm actually in a place where I can do that. I switched jobs and moved relatively recently, and aside from the pain problems, life's going really well. The amputation stuff definitely affects people's perceptions of me, which is frustrating, and I still have to deal with every stupid aspect of our fucked-up health-care system and the way the medical suppliers bleed everybody else dry so they can maintain their markups, but I can deal with that at least. Now I just need to get past the surgery, lose some weight, and get back up on the prostheses so I can get back into things all the way.” (...)

\subsection{Effects of Psychotherapy, Psychopharmacological Medication and Relaxation Techniques}

All participants had resisted their desire for years and many tried to avoid the operation with different kinds of therapies. 
The participants were asked to give us information about these therapies (i.e. psychotherapy, pharmacological treatment and relaxation techniques).

Seven persons $(33.3 \%)$ never had any treatment, while others tried more than one kind of therapy. Six BIID-sufferers (28.6\%) participated in psychoanalysis and another seven $(33.3 \%)$ in behavioral therapy; three (14.3\%) had depth-psychology, twelve $(57.1 \%)$ had counseling before surgery, one $(4.8 \%)$ psychodrama and another chose the category "other psychotherapy". Only two persons said, they felt a profit from the therapy, all of them had counseling therapy. In contrast the desire for amputation increased in five other cases during a therapy (see Tab. 4).

Table 4 Change of the wish for amputation in the group of patients who had psychotherapy before the operation.

\begin{tabular}{ll}
\hline Effect of psychotherapy & $\begin{array}{l}\text { Number (percent) of } \\
\text { participants with psychotherapy }\end{array}$ \\
\hline Considerable decrease of BIID desire & $1(6.3 \%)$ \\
Little decrease of BIID desire & $1(6.3 \%)$ \\
No influence on BIID desire & $9(56.3 \%)$ \\
Little increase of BIID desire & $2(12.5 \%)$ \\
Considerable increase of BIID desire & $3(18.8 \%)$ \\
\hline
\end{tabular}

Twelve persons had taken psychopharmacological medications, some of them up to 3 different kinds of medicine. Ten $(83.3 \%)$, i.e. most of them, got antidepressant, two $(16.7 \%)$ neuroleptica, another two $(16.7 \%)$ tranquilizer and four $(33.3 \%)$ tried other medications to reduce the desire for amputation. These medications had no positive effects, about two thirds of these twelve patients stated that the desire for surgery was constant and in about one third the BIID-desire increased (see Tab. 5).

Thirteen persons used relaxation techniques, several tried different methods, one of them up to five different kinds. Eight $(61.5 \%)$ autogenic training, seven $(53.8 \%)$ mediation and five $(38.5 \%)$ the progressive muscle relaxation, Yoga and QiGong were used by one person each $(7.7 \%)$, two participants chose the category "others" (15.4\%). The majority of these persons did not profit from relaxation techniques. Due to the concentration on the body, the BIID desire increased in $53.9 \%$ (seven persons), only two persons (15.4\%) stated decreased wishes for amputation (one used autogenic training, the other progressive muscle relaxation), there was no clear change in the remnant $30.8 \%$ (four persons), see Table 6.

Table 5 Change of the wish for amputation in the group of patients who had psychopharmacological medication in the years before the operation.

\begin{tabular}{ll}
\hline $\begin{array}{l}\text { Effects of psychopharmacological } \\
\text { medication }\end{array}$ & $\begin{array}{l}\text { Number (percent) of } \\
\text { participants with } \\
\text { pharmacotherapy }\end{array}$ \\
\hline Considerable decrease of BIID desire & $0(0.0 \%)$ \\
Little decrease of BIID desire & $0(0.0 \%)$ \\
No influence on BIID desire & $8(72.7 \%)$ \\
Little increase of BIID desire & $1(9.1 \%)$ \\
Considerable increase of BIID desire & $2(18.2 \%)$ \\
\hline
\end{tabular}

Table 6 Change of the wish for amputation in the group of patients who had learned a relaxation technique before the operation.

\begin{tabular}{ll}
\hline Effect of relaxation techniques & $\begin{array}{l}\text { Number (percent) of } \\
\text { participants with relaxation } \\
\text { techniques }\end{array}$ \\
\hline Considerable decrease of BIID desire & $0(0.0 \%)$ \\
Little decrease of BIID desire & $2(15.4 \%)$ \\
No influence on BIID desire & $4(30.8 \%)$ \\
Little increase of BIID desire & $5(38.5 \%)$ \\
Considerable increase of BIID desire & $2(15.4 \%)$ \\
\hline
\end{tabular}

\subsection{Effects on Mental Disorders}

In cases of involuntarily amputation, e.g. due to accidents or diabetes-necrosis, mental disorders as depression or anxiety are reported quite often. In the next part, our questionnaire investigated, whether this is the case in a desired amputation, too. We surveyed the appearance of anxiety, depression, concentration deficits, sleeping disorders and psychosomatic disorders before and after having surgery. Those disorders, if existing, significantly decreased (see Tab. 7).

Table 7 Extent of emotional and psychosomatic disorders before and after the operation on a 0 to 100 scale.

\begin{tabular}{llll}
\hline Disturbance & $\begin{array}{l}\text { before OP } \\
(\text { mean } \pm \text { SD) }\end{array}$ & $\begin{array}{l}\text { after OP } \\
(\text { mean } \pm \text { SD) }\end{array}$ & $\begin{array}{l}\text { Wilcoxon } \\
\text { Test }\end{array}$ \\
\hline anxiety & $23.5 \pm 26.0$ & $3.8 \pm 9.2$ & $\mathrm{p}<.01$ \\
depression & $41.0 \pm 33.2$ & $2.4 \pm 7.0$ & $\mathrm{p}<.001$ \\
concentration deficits & $43.0 \pm 31.1$ & $3.8 \pm 8.1$ & $\mathrm{p}<.001$ \\
sleep disorders & $29.0 \pm 33.7$ & $2.4 \pm 5.4$ & $\mathrm{p}<.001$ \\
psychosomatic disorders & $17.5 \pm 28.1$ & $1.0 \pm 3.0$ & $\mathrm{p}<.05$ \\
\hline
\end{tabular}

One argument against a legalization of amputation for persons with BIID is that these people may utter a desire for more surgeries, when the first one is done. Therefore in our questionnaire we asked whether they desire further surgeries. Seventeen out of 20 persons (1 m.d.) stated that they do not feel a desire for any other surgery. Two felt a wish for an additional right above the elbow amputation, one stated the wish for a double above the knee amputation and another one wish a left above the elbow amputation.

\subsection{To Whom do They Tell the Truth?}

An amputation leads to a handicap, in addition to the psychosocial reactions of the surrounding people, this has several financial consequences, e.g. the after-care must be paid by the insurance, in several patients the abilities to do their work can be restricted and partially the patient need an education for another job. While there is no problem with payments of the health care system, when the amputation is due to an accident or an illness, a self-afflicted handicap can lead to juristically embarrassments. Therefore, at first nearly all operated BIID sufferers claimed to have had an accident or a severe infection. On the other hand, an appreciative social environment is very important for long-term satisfaction and it may be important to these people to have somebody to talk about their situation. Here the question emerges, do they tell the truth to good friends and close relatives?

Sixteen (out of 20) of the participants (76.2\%) stated that they have told their families the true reasons for amputation; 
twelve out of $20(57.1 \%)$ told their friends as well. In contrast, colleagues were rarely informed in most cases (6 out of 19, $28.6 \%$ ).

\subsection{Phantom Limb Feelings}

Another part of the questionnaire investigated the presence of phantom limb pain which could cause strong restrictions for persons concerned. Missing phantom limb feelings would support the theory of a failure of embedment of the amputated leg or arm into the body scheme of BIID-persons.

Fifteen out of 18 participants $(83.3 \%)$ had normal feelings of pain at the stump after the operation. The mean of this pain on a $0-100$ scale was $22.8 \pm 26.1$. Seventeen out of 18 of the participants (94.4\%), who answered this question, stated that have phantom limb pain. The mean of phantom limb pain on a 0 to 100 scale was $28.9 \pm 30.7$. Seventeen out of 18 participants $(94.4 \%)$ felt sensations in their phantom limbs. The mean of the frequency of these phantom feelings on a "not at all $0-100$ very often" scale was $55.3 \pm 36.8$. In ten participants $(55.5 \%)$ these feelings began directly after the operation, in three $(16.6 \%)$ some days later, in one $(5.5 \%)$ after some weeks, in three (16.6\%) after some months and in one $(5.5 \%)$ these feelings emerged after several years. The participants described these feelings as: itching $(n=11)$, needles \& pins $(n=9)$, pressure $(n=7)$, limb feels smaller than natural $(n=3)$, longer $(n=1)$, shorter $(n=1)$, warmer $(n=2)$, colder $(\mathrm{n}=1)$, and "others" $(\mathrm{n}=4)$.

The question: "Do you sometimes forget that your body limb has been amputated?" was asked on a scale "not at all 0 to 100 very often". Only three out of 19 patients never forgot to be handicapped. The mean of the other 16 was $65.0 \pm 35.6$, i.e. they tended often to forget, that they are disabled. For the 16 who answered "yes", our next question asked: "Do you intuitively use it?" six out of these 16 persons (37.5\%) never tried to use the non-existing limb. The mean of the other nine $(62.5 \%)$ was $34.4 \pm 29.2$, i.e. they tended rarely to use the amputated limb intuitively.

Whenever phantom limb pain was observed most persons (12 out of 19 persons, $63.2 \%$ ) feel absolutely not impaired in their quality of life (on a scale from 0 to 100). For the other seven the mean was $32.9 \pm 24.3$.

\subsection{Dreams}

Phantom limb pain seems to influence the way of dreaming of the own body [34]. The question: "Have you ever dreamed of yourself as an amputee before the operation?" was answered from 19 persons. Only two (10.5\%) crossed the alternative "never". Three (15.8\%) participants remembered one or two dreams like this, four $(21.1 \%)$ said they remember about 3-10 amputee-dreams and ten (52.6\%) had more than 10 dreams.

In addition, we asked, whether the participants after the operation dreamed of themselves with their old (intact) body or with their new (amputated) body. Nineteen subjects were able to remember dreams and to answer this question. Only three $(15.8 \%)$ had mostly an intact body in their dreams $(n=1$ always), twelve subjects $(63.2 \%)$ felt in most dreams as an amputee ( $\mathrm{n}=3$ always), and in three $(15.8 \%)$ both was about equally frequent. One subject $(5.2 \%)$ wrote that the body in dreams is different to the actual body but the person didn't describe it in detail.

The time in which the switch from an unimpaired body to a disabled body took place in the dreams was very different. Only fourteen subjects were able to answer this question. Sometimes it was within a few days $(n=7,50 \%)$ or weeks $(n=3$, $21.4 \%)$ or months $(n=3,21.4 \%)$, only one person said, this was the case after years $(n=1,7.2 \%)$.

Some typical dreams were: "Before the operation I nearly always dreamed about amputation or poliomyelitis (my real BIID-goal). After I lost my leg, my dreams changed. The dreams never affect the concrete number of my legs. I'm interpreting this in the way that amputation doesn't any longer bother me, because I don't have BIID any longer."; "Mostly I dream of being in my body as it is now. Immediately after amputation, I often dreamed of still having two legs. Not as an important part of the dream, just as background."; "I saw how I ride my bicycle or motorcycle with one leg. Or I sit with my stump on the hand-grip of the crutch and jump around on the sandy beach."; "It was nice to see myself in my dream, around me all surgeons, doing a leg amputation. It was a disappointment after waking up, out of this dream."; "I drove with my wheel-chair through a long floor of a manor house into my garden, which looked like a park. Birds were chirping and this makes me awake." (...)

\subsection{Pretending Behavior and Body Feelings}

There were some additional questions we tried to answer with our investigation. One question was, whether the frequency of pretending behavior has any relation to how the person judged the affected limb. We found a small, but significant correlation of $\mathrm{r}=0.44(\mathrm{p}<0.05)$ between the question "How much differed the body part you had amputated from the rest of your body? Not belonging to very belonging to $m e$ " (on a -50 to +50 scale) with the frequency of pretending behavior (on a 0 to 100 scale).

\subsection{Use of Prostheses and Body Feeling}

One strange fact is that many BIID-amputees are using prostheses after the amputation. At last with this device they rebuild a status they have had before with their real limb. We had the theory that the more belonging and soulful this limb has been before the amputation, the higher the chance that the subject will tend to replace it with a prosthesis. Therefore we analyzed the correlation between the results of the question "Are you using prostheses and devices in order not to appear handicapped" (on a "never -50 to +50 very often" scale) and "how much differed the body part you had amputated from the remnant of your body" and found:

Very soulless - very soulful: $r=0.53(\mathrm{p}<0.05)$

Not belonging - very belonging to me: $r=0.49(\mathrm{p}<0.05)$

Very disgusting - very beautiful: $r=0.52(\mathrm{p}<0.05)$

Though these significant correlations support our theory, 
it's hard to explain then why the limb still was amputated even when the person has had feelings of belonging and soulfulness.

\section{Discussion}

To be disabled would be a worse fate for most of us who are owner of a healthy body. At first glance it is unbelievable that someone claims to be happy only after changing his or her intact body into a handicapped one. Until now it's not clear why and how this wish developed. Still all of us know desires, which, once they emerged, are hardly to get rid of. But the wish to have a new pair of shoes, to buy a motorcycle or to find a new intimate partner is by far not the same desire compared with the loss of a leg or an arm. Or, to overdraw this point, some depressive people are feeling a strong urge to commit suicide; it is their desire to be dead. The question emerges, when and how can the health care system help these people and when do we have to protect them from their own wishes? Must the society prevent, when somebody wants an amputation of an otherwise healthy limb? The here presented results have no need to struggle with ethical and juristic limitations of a desired amputation, because all people, who were interrogated in our study, had already achieved their wish The major goal of our study was the question, whether an amputation or another kind of surgery really helped people suffering from BIID in the long run?

Our sample included $85.7 \%$ men and $14.3 \%$ women, this relation is consistent with the results from other studies showing that more men than women seem to be affected by BIID. 76.2\% were heterosexual, and $9.5 \%$ homosexual. Thus the percentage of homosexuals is higher than in the total population, but lower than the postulated number of Stirn [10].

The most frequent impairment in our study was an amputation left above the knee. This preference for the left side is confirmed by other studies [e.g. 10, 3] and was explained by the cause that driving an automobile is possible when you lost your left leg [7, 36]. Other disabilities, which were more than once reported, were leg amputations and palsy. Most discussions about BIID consider only amputations, but in our study several other impairment were figured out. In five of 21 cases $(23.8 \%)$, the desired impairment was not or not exclusively an amputation of a limb. Thus, the focus of a quarter of the persons is not only to the loss of a limb.

Our first task was to investigate motives. As in other studies the motivations were still unclear. Most subjects remembered that the wish emerged in childhood and adolescence, often after viewing a disabled person. In contrast to normal children, who react with sadness, when they see such a "poor" handicapped amputee, the BIID-subjects were fascinated and developed the idea to be like these disabled people.

All of them tried to fight against their wish for decades of years. Years of pondering about a question without to be able to find a solution, costs a lot of energy. This is not typical for BIID but also the case in several other situations of the life, e.g. when a person is unable to decide whether he or she better should divorce from a partner or change a job with good earnings but a worse boss. The lasting musing about the pros and cons draws considerable energy from activities of daily living. This may explain, that all BIID subjects wrote they have had feelings of depression before the operation and felt free, when they had achieved the desired operation.

In contrast to patients with an amputation due to accidents or infections, BIID-afflicted persons are feeling joyful after the amputation. They listed several disadvantages, but in total they said that the advantage to have reached their goal outbalanced these disadvantages by far. A lot of areas of life changed for these persons after the amputation, but these changes are not felt as wearing but as exonerative. The reported improvements are not only descriptively but also statistically relevant. Our detailed questions about the emotions and thoughts short after the operation, one year later and now show that these modifications are not short term-improvements but long term.

In contrast to body dysmorphic disorder (BDD) is in BIID subjects only a very small tendency to judge the attractiveness of the concerned limb as "unaesthetic" and "disgusting", much more they have the feeling it is "soulless" and "not belonging" to the self. So we can confirm there is a difference between BDD and BIID.

Since there is no known therapy that seems to promise a healing from BIID, amputation has to be considered as a possibility to help these persons. In the foreground stands the quality of life, which is crucial for success or failure of therapy. Our results lead to the conclusion that for this sample of persons an improvement in quality of life is recognizable. Mental disturbances decreased. Wishes for further surgeries were seen in some participants, but all claimed to have had these desires before their first operation.

Frequently participants stated that living with BIID and not being helped by surgery is the worst case. But, next to an operation, we must ask, whether it can give other ways to help these people? In our study counseling therapy had a decent effect on the desire for amputation. We found no clear effect of other psychotherapeutic methods or relaxation techniques or psychopharmacological treatment. There is a restriction of these results, because we only asked for the kind of therapy, but missed to ask how long the subjects have had it. On the other hand it must be said, that in some participants the wish for amputation increased due to one of these methods. In our opinion there can be a risk that due to talking about BIID the attention of the patients was focused more on this wish. Especially relaxation technique draws the attention to the body and increased the desire in some subjects. These conclusions are restricted, because in our study we only investigated people who decided pro operation. At last this decision was based on the fact, that no other therapy has had any sufficient effect, i.e. the results presented here do not mean that therapy can not have any effects on all BIID affected people. Those therapies were only ineffective for most of the persons being asked in this sample, otherwise participants would not have had surgery. Until now there exists no standardized therapy study with a larger group of BIID sufferers to determine, whether a therapy is helpful for 
these persons or not.

Certainly there has to be further research on how to improve psychotherapy for people with BIID and to make it more effective. As Müller [22] stated, it would be reprehensible to amputate healthy body parts when there is an efficient alternative therapy. Oliver Sacks [35] reported a possible method. He used music therapy to reach a state in which he accepted his leg again.

In our study there was only one out of 21 subjects who suffered from heavy side effects and even this person judged it better to have fulfilled his wish than to suffer longer from grieves due to BIID. Most of the persons report that they had suffered more from BIID than from any disadvantage in a life as a disabled person. There are no reports of regrets even when complications occurred. It can be assumed that the positive identification with the own body after surgery, neutralize negative effects of BIID. Those effects are solid even for the longer term.

As said in the introduction, a current explanation for the cause of BIID is a dysfunction of the parietal lobe, in which the body is represented [30, 31, 32, 33]. If this theory is right, amputated BIID patients should not have any phantom limb feelings. Our data shows that most subjects, we interrogated, had phantom limb feelings. Possibly these results contradict the theory. But we have to assume, that phantom limb feelings depend on an intact somato-sensory area in the parietal lobe. This area clearly is undamaged in BIID-sufferers, otherwise they would have been be unable to have sporting activities before the operation. The body-scheme may lay in another parietal area, which is perhaps not responsible for phantom-limb feelings.

The results about dreams we found, do not clearly support any theory. Some of our subjects dreamed to be amputated before the operation, some dreamed to have all limbs short after the operation. We found no clear pattern, but all subjects dreamed of themselves as handicapped very fast after the operation. For an explanation of these results we should have had a group of amputated people due to accident or infections, but this was not the central goal of our study.

\section{Conclusion}

As long as there is no alternative therapy like this, people with BIID still need to be helped. Most of them live with BIID for decades of years and many of them decide they do not have more time to wait for results of any scientific studies to come. So it is important to think of any help that can be given to people with BIID now. Most of concerned persons state a high level of suffering especially in reported cases of self-amputations. Levy [26] already claimed legal amputation surgery for people with BIID as soon as it is obvious that the disorder is hard to treat. Right now the only effective way to help seems to be the surgery. For that reason and for reasons of autonomy, amputation should be recognized as one possible way of therapy and should be permitted once further studies find similar results.

Enrolling of BIID in a Classification Systems as ICD or
DSM may be a good start. Further therapies must be developed. In addition a legalization of such amputations has to be discussed. Nowadays we have several surgical operations such as e.g. breast-implants (which can cause back issues) or nose correction for young clients (even though their noses still grow), or surgery on infants who are born with a "not identifiable genital". These surgeries are legal. However, amputation in BIID subjects created a body which does not correspond with human's ideal of beauty. It brings out a disabled body and the human society is afraid to be handicapped. Our results show that the amputation had helped all BIID affected subjects and, as long as no other therapy exists, it may be better to help these people with an operation than to take the risk of deliberate accidents or operations somewhere in developing countries.

\section{Acknowledgements}

We want to thank Prof. Peter Brugger for the support of this study with a lot of important ideas and for the collaboration on the questionnaire.

\section{References}

[1] R. Barnes, "The bizarre request for amputation", The International Journal of Lower Extremity Wounds, 10(4), 2011, pp 186-189.

[2] P. Brugger, "The wish for amputation - bizarre quirk or neurological disorder?", Transl. J. Ars medici, 2, 2011, pp 1-5. [Der Wunsch nach Amputation - Bizarre Macke oder neurologische Störung?]

[3] M.B. First, "Desire for amputation of a limb: paraphilia, psychosis or a new type of identity disorder", Psychological medicine, 34, 2005, pp 1-10.

[4] M.B. First, and C.E. Fisher, "Body Integrity Identity Disorder: The persistent desire to acquire a physical disability", Psychopathology, 45, 2012, pp 3-14.

[5] G. Furth and R. Smith, "Apotemnophilia: Information, Questions, Answers, and Recommendations about self-demand Amputation”. Bloomington, IN: 1st Books Library, 2000.

[6] A.J. Johnson, S.-L- Liew and L. Aziz-Zadeh, "Demographics, learning and imitation, and body schema in Body Integrity Identity Disorder", Indiana University Undergraduate Journal of Cognitive Science, 6, 2011, pp 8-15.

[7] E. Kasten, "Body Integrity Identity Disorder (BIID): Interrogation of people concerned and explanatory approaches", Transl. J. Fortschritte der Neurologie und Psychiatrie, 77, 2009, pp 16-24 [Body Integrity Identity Disorder (BIID): Befragung von Betroffenen und Erklärungsansätze.].

[8] E. Kasten and F. Spithaler, "Body Integrity Identity Disorder: personality profiles and investigation of motives," in Body Integrity Identity Disorder, A. Stirn, A. Thiel and S. Oddo, Eds. Lengerich: Pabst Science Publishers, 2009, pp 20-40.

[9] A. Stirn, A. Thiel and S. Oddo, "Body Integrity Identity Disorder: psychological, neurobiological, ethical and legal aspects", Lengerich: Pabst, 2009. 
[10] A. Stirn, A. Thiel and S. Oddo, "Body Integrity Identity Disorder: clinical picture, diagnosis, therapeutic approaches", Transl. B. Weinheim: Beltz, 2010. [Body Integrity Identity Disorder: Störungsbild, Diagnostik, Therapieansätze].

[11] I. Martin, „Mancophilia - appearance and interactions“, Transl. B. Maintal: Homo-Mancus, 2010. [Mancophilie Erscheinungsformen und Interaktionen].

[12] W. Everaerd, "A case of apotemnophilia: a handicap as sexual preference", American Journal of Psychiatry, 37(2), 1983, pp 285-293.

[13] J. Money and K.W. Simcore, "Acrotomophilia, sex and disability: new concepts and case report", Sexuality and Disability, 7(12), 1986, pp 43-50.

[14] V.S. Ramachandran, D. Brang, P.D. McGeoch and W. Rosar, 'Sexual and food preference in apotemnophilia and anorexia: interactions between 'beliefs' and 'needs' regulated by two-way connections between body image and limbic structures", Perception, 38(5), 2009, pp 775-777.

[15] P.D. McGeoch, D. Brang, T. Song, R.L. Lee, M. Huang and V.S Ramachandran, "Xenomelia: a new right parietal lobe syndrome", JNNP, DOI, 10.1136/jnnp-2011-300224, 2011.

[16] F. Spithaler and E. Kasten, "epidemiological examination of the incidence of changes in body perception", Transl. J. Zeitschrift für Medizinische Psychologie, 2012. [Epidemiologische Untersuchung der Inzidenz von Veränderungen der Körperwahrnehmung].

[17] D. Neff and E. Kasten, "Body Integrity Identity Disorder (BIID): What do health care professionals know?", European Journal of Counselling Psychology, 1(2), 2009, pp 16-30.

[18] D. A. Veale, "Compelling Desire for Deafness", The Journal of Deaf Studies and Deaf Education, 11(3), 2006, pp 369-372.

[19] A.W. Braam, S. Visser, D.C. Cath and W.J.G. Hoogendijk, "Investigation of the syndrome of Apotemnophilia and course of a cognitive-behavioral therapy", Psychopathology, 39, 2006, pp 32-37.

[20] A.W. Braam and N. de Boer-Kreeft, "Case-Report - The ultimative relief: resolution of the apotemnophilia syndrome" in Body Integrity Identity Disorder, A. Stirn, A. Thiel and S. Oddo, Eds. Lengerich: Pabst Science Publishers, 2009, pp 70-78.

[21] A, Thiel, S. Oddo, S. Skoruppa, J. Thiel, F. Ehni, D. Bennett and A. Stirn, "Psychotherapy- and psychometric research with BIID-sufferers", in Body Integrity Identity Disorder: psychological, neurobiological, ethical and legal aspects, A. Stirn, A. Thiel, S. Oddo, Eds. Lengerich: Pabst, 2009, pp 58-69.

[22] S. Müller, "BIID, is the wish for amputation an autonomic decision or a manifestation of a neurological disorder?", Transl. B. in Normal-anders-krank? Akzeptanz, Stigmatisierung und Pathologisierung im Kontext der Medizin, D. Groß, S. Müller \& J. Steinmetzer, Eds. Berlin: Medizinisch wissenschaftliche Verlagsgesellschaft, 2008, pp 229-2669. [BIID, ist der
Amputationswunsch eine autonome Entscheidung oder Ausdruck einer neurologischen Störung?].

[23] T. Bayne and N. Levy, "Amputees by choice: Body Integrity Identity Disorder and the ethics of amputation", Journal of Applied Psychology, 22(1), 2005, pp 75-85.

[24] J. Beckford-Ball, "The amputation of healthy limbs is not an option”, British Journal of Nursing, 9(4), 2000, pp 188.

[25] A. Bridy, "Confounding extremities: surgery at the medico-ethical limits of self -modification", The Journal of Law, Medicine \& Ethics, 32(1), 2004, pp 148-158.

[26] N. Levy, "Neuroethics". Cambridge: University Press, 2007.

[27] S. Müller, "Body Integrity Identity Disorder (BIID) - Is it possible to ethically justify the amputation of limbs?", Transl. J. Ethik in der Medizin, 20(4), 2008, pp 287-299. [Body Integrity Identity Disorder (BIID) - Lassen sich Amputationen gesunder Gliedmaßen ethisch rechtfertigen?].

[28] A. Manok, "Body Integrity Identity Disorder: the legitimacy of amputations of healthy limbs", Transl. B. Leipzig: Leipziger Universitätsverlag, 2012. [Body Integrity Identity Disorder: Die Zulässigkeit von Amputationen gesunder Gliedmaßen aus rechtlicher Sicht].

[29] K. Nitschmann, (2007). "Surgery for the soul?", Transl. J. Zeitschrift für die gesamte Strafrechtswissenschaft, 119, 2007, pp 547-592. [Chirurgie für die Seele?]

[30] D. Brang, P.D. McGeoch and V.S. Ramachandran, „Apotemnophilia: a neurological disorder”, Neuro Report, 19(13), 2008, pp 1305-1306.

[31] A. Sedda, "Body Integrity Identity Disorder: from a psychological to a neurological syndrome", Neuropsychology Review, 21(4), 2011, pp 334-336.

[32] D. Vitacco, L. Hilti and P. Brugger, "A neurological account of Body Integrity Identity Disorder", in Body Integrity Identity Disorder: psychological, neurobiological, ethical and legal aspects, A. Stirn, A. Thiel, S. Oddo, Eds. Lengerich: Pabst, 2009, pp 201-210.

[33] V.S. Ramachandran, "Adventures in behavioral neurology-or-what neurology can tell us about human nature", http://edge.org/ conversation/ adventures_behavioral_neurology, 2012.

[34] P. Brugger, "The phantom limb in dreams", Consciousness and cognition, (17), 2008, pp 1272-1278.

[35] O. Sacks, "A Leg to Stand On”. London: Gerald Duckworth \& Co. Ltd, 1984.

[36] E. Kasten and A. Stirn,. "The wish for an amputation changes from the right to the left site in Body Integrity Identity Disorder", Transl. J. Zeitschrift für Psychiatrie, Psychotherapie und Psychologie, 57, 2009, pp 55-61. [Wechselnder rechts-links-Amputationswunsch bei Body Integrity Identity Disorder (BIID)]. 